\title{
Proliferation of estrogen-responsive mouse tumor cell line B-1F stimulated by Saiboku-to, but inhibited by Scutellaria baicalensis, a component of Saiboku-to
}

\author{
TERUKO MURASHIMA ${ }^{1,2,3}$, MEGUMI YAMASAKI ${ }^{1,3}$, YOSHIO NISHIZAWA ${ }^{4,5}$, HIROSHI KATAYAMA $^{1,3}$, \\ YUMIKO TANIGAKI $^{1}$, YOSHIKO SAEKI ${ }^{1}$, KIMURA SHOJIRO ${ }^{2}$ and YASUKO NISHIZAWA $^{1,3}$ \\ ${ }^{1}$ Department of Pathology, Research Institute, Osaka Medical Center for Cancer and Cardiovascular Diseases, 1-3-2, \\ Nakamichi, Higashinari, Osaka 537-8511; ${ }^{2}$ Department of Radiochemical Laboratory, Osaka University of Pharmaceutical \\ Sciences, Takatsuki, Osaka 569-1094; ${ }^{3}$ Laboratory of Clinical and Experimental Pathophysiology, Graduate School of \\ Pharmaceutical Science, Osaka University, Osaka 565-0871; ${ }^{4}$ Department of Dynamic Pathology, Research Institute \\ for Neurological Diseases and Geriatrics, Kyoto Prefectural University of Medicine, Kamigyoku, Kyoto 602-8566; \\ ${ }^{5}$ Department of Anesthesiology, Shiga University of Medical Science, Ohtsu, Shiga 520-2192, Japan
}

Received February 25, 2009; Accepted May 4, 2009

DOI: $10.3892 /$ or_00000432

\begin{abstract}
We have demonstrated that the proliferation of estrogen-responsive mouse Leydig tumor cell line B-1F is induced via suppression of 5-lipoxygenase activity followed by decrease of leukotrienes (LTs). Additionally, it has been reported that LTD4 induces apoptosis in B-1F cells. In this study, we examined effects of Saiboku-to, a traditional Chinese medicine having suppressive activities for LT production and release, on the proliferation. Saiboku-to promoted, but Scutellaria baicalensis, one of components (herbs) of Saiboku-to, significantly inhibited the proliferation of $\mathrm{B}-1 \mathrm{~F}$ cells in vitro and in vivo. The action of Scutellaria baicalensis in B-1F cells was studied in more detail. Although Scutellaria baicalensis consists of flavonoids, iridoids, volatile oils and others, it and its major constituents had no direct effect on estrogen binding sites in B-1F cells. B$1 \mathrm{~F}$ cells treated with Scutellaria baicalensis showed morphological changes such as nuclear aggregation and fragmentation. DNA fragmentation was also observed, indicating that Scutellaria baicalensis induces apoptosis in $\mathrm{B}-1 \mathrm{~F}$ cells and that it or its constituents might be a good resource for searching new drugs, especially anti-cancer drugs. Moreover, Saiboku-to promoted B-1F cell proliferation, but Scutellaria baicalensis inhibited it, showing complexity of action of traditional Chinese medicines.
\end{abstract}

Correspondence to: Dr Yasuko Nishizawa, Department of Pathology, Research Institute, Osaka Medical Center for Cancer and Cardiovascular Diseases, 1-3-2, Nakamichi, Higashinari, Osaka 537-8511, Japan

E-mail: nisizawa-ya@mc.pref.osaka.jp

Key words: Saiboku-to, Scutellaria baicalensis, proliferation, apoptosis

\section{Introduction}

Arachidonic and linoleic acid metabolites play important roles in carcinogenesis $(1,2)$. We have reported that 5-lipoxygenase (5-LOX) activity and leukotriene (LT) production in $\mathrm{B}-1 \mathrm{~F}$ cells are decreased, when the proliferation of $\mathrm{B}-1 \mathrm{~F}$ cells is stimulated by $17 ß$-estradiol (E2) and that LTD4 induces apoptosis in B-1F cells (3-10).

Traditional Chinese medicines have been used for treatments of acute and chronic diseases because side effects caused by them are thought to be relatively mild. In many cases, they have been used as anti-inflammatory drugs, but now it is known to have various kinds of actions. These medicines are used as health foods and quasi-drugs and are used in combination with other therapeutic drugs for lifestyle-related diseases including diabetes mellitus $(11,12)$. A traditional Chinese medicine is composed of many components (herbs) and shows various pharmacological actions, whose mechanisms are not well understood. Anticarcinogenic action and induction of apoptosis by herbs are of great interest.

Saiboku-to suppresses LT production and release and is often medicated for bronchial asthma. Therefore, we examined effects of Saiboku-to on B-1F cells. Saiboku-to is composed of ten herbs; Latin names are Bupleuri Radix, Pinelliae Tuber, Hoelen (Poria), Scutellariae Radix (scientific name is Scutellaria baicalensis), Magnoliae Cortex, Zizyphi Fructus, Ginseng Radix, Glycyrrhizae Radix, Perillae Herba and Zingiberis Rhizoma in 7.0, 5.0, 5.0, 3.0, 3.0, 3.0, 3.0, 2.0, 2.0 and 1.0 parts (Tsumura), respectively. In the present study, action of Scutellaria baicalensis, a component contained in Saiboku-to, is also examined, using B-1F cells.

\section{Materials and methods}

Preparation of traditional Chinese medicine and herb extracts. The herb powder was suspended in phosphate-buffered saline 
(PBS) at a concentration of $20 \mathrm{mg} / \mathrm{ml}$ (wt of the powder/ solvent volume). The suspension was sonicated three times for $45 \mathrm{sec}$ each at the maximum setting. After centrifugation at $1,000 \mathrm{x} \mathrm{g}$ at room temperature for $15 \mathrm{~min}$, the supernatant was collected, filtered through $0.22-\mu \mathrm{m}$ pore size filter and stored at $4^{\circ} \mathrm{C}$ as a stock solution until use. Saiboku-to was reconstituted with its components and the working solution of Saiboku-to lacking various components was also prepared. Some experiments were performed by using a combination of these solutions.

Cell culture. B-1F cells were maintained in Eagle's minimum essential medium-Ham's F12 (1:1, vol/vol) containing $0.1 \%$ (wt/vol) bovine serum albumin (BSA) (HMB medium) supplemented with $10^{-8} \mathrm{M}$ E2 (HMBE medium). Cells were grown at $37^{\circ} \mathrm{C}$ in a humidified $5 \% \mathrm{CO}_{2}$ atmosphere to confluence and passaged using trypsin $(0.01 \%$, wt/vol)-EDTA $(0.02 \%, w t / v o l)$ in PBS.

In vitro cell growth experiments. Cells were treated with various concentrations of Saiboku-to or its components. Cell growth experiments were carried out, as previously published (3).

In vivo growth. Animal experiments were carried out using previously described methods $(3)$. B-1F cells $\left(5 \times 10^{5}\right.$ cells $)$ dispersed in $0.2 \mathrm{ml}$ MEM were injected subcutaneously (s.c.) into castrated male Balb/c mice. The following day (day 0) mice were implanted a fused pellet of $1 \% \mathrm{E} 2$ in cholesterol and fed with or without extract of $0.1 \%$ (wt/vol) Scutellaria baicalensis in distilled water. Tumor growth was monitored by measuring tumor volume at indicated intervals. The tumor volume (v) was calculated by the formula; $v=4 / 3 \pi(a / 2 x b / 2)^{3 / 2}$, where ' $a$ ' and ' $b$ ' are, respectively, the largest and the smallest diameter of the tumor (13).

Analysis of estrogen binding sites. The whole cell binding assay was used to obtain the binding parameters of estrogen binding sites in B-1F cells, as previously published $(5,9,14)$. Briefly, B-1F cells $\left(2 \times 10^{6}\right.$ cells $)$ were incubated with $5 \mathrm{nM}$ $\left[2,4,6,7-{ }^{3} \mathrm{H}(\mathrm{N})\right]$ Estradiol $\left(\left[{ }^{3} \mathrm{H}\right] \mathrm{E} 2\right)$ in the presence of various concentrations of Scutellaria baicalensis or Saiboku-to for $60 \mathrm{~min}$ at $37^{\circ} \mathrm{C}$. These incubated cells were washed four times with ice-cold HMB medium and the cell pellets were transferred to scintillation vials for the determination of the radioactivity specifically associated with the cells. For the cellfree binding assay, B-1F cells were incubated with HMB medium for $2 \mathrm{~h}$ and the medium was replaced with the fresh medium. The following day, the cells were homogenized in 5 $\mathrm{ml}$ ice-cold TED-Mo-L/pH 7.4 buffer (10 mM Tris, 1.5 mM EDTA, $10 \mathrm{mM}$ DTT, $10 \mathrm{mM} \mathrm{Na} \mathrm{MoO}_{4}$ containing 0.2 $\mathrm{mg} / \mathrm{ml}$ leupeptin). Since estrogen binding sites in B-1F cells are found to be tightly associated with crude nuclei even in the absence of any estrogenic stimuli (6), binding analysis was performed using the nuclear fraction. After centrifugation at $800 \mathrm{x} \mathrm{g}$ for $10 \mathrm{~min}$ at $4^{\circ} \mathrm{C}$, the crude nuclear pellets were washed four times with ice-cold TED-Mo buffer/pH 7.4, suspended in $1 \mathrm{ml}$ of TED-Mo-10\% glycerol buffer using Dounce homogenizer and passed through a $100-\mu \mathrm{m}$ filter. Aliquots of the nuclear fraction were incubated with $5 \mathrm{nM}$ $\left[{ }^{3} \mathrm{H}\right] \mathrm{E} 2$ in the presence of various concentrations of Scutellaria baicalensis for $60 \mathrm{~min}$ at $37^{\circ} \mathrm{C}$. These incubated homogenates were washed once with TED-10\% glycerol$0.25 \%$ Triton X-100 and then twice with TED-Mo buffer. After centrifugation, the pellets were transferred to scintillation vials for the determination of the radioactivity.

Detection of apoptosis. Apoptosis was determined by morphological examination, immunohistochemistry for singlestranded DNA (ssDNA) and DNA fragmentation analysis. For morphological examination $\mathrm{B}-1 \mathrm{~F}$ cells were seeded at a density of $5 \times 10^{3}$ cells/35-mm dish in $2 \mathrm{ml} \mathrm{HMB}$ medium. The following day (day 0 ), the medium was changed to HMB or HMBE medium with or without Scutellaria baicalensis $(50 \mu \mathrm{g} / \mathrm{ml})$. On day 2, the cells were washed in PBS and fixed in $2 \%$ glutaraldehyde in $0.1 \mathrm{M}$ phosphate buffer for $2 \mathrm{~h}$ at $4^{\circ} \mathrm{C}$ in the dark. After washing, the cells were stained with Hoechst 33342 (final concentration $0.167 \mathrm{mM}$ ) and observed by a fluorescence microscope. For immunohistochemistry for ssDNA, on day 3, B-1F cells were washed in PBS and fixed in $4 \%$ paraformaldehyde for $15 \mathrm{~min}$ at $4^{\circ} \mathrm{C}$. After washing in PBS, the cells were treated with $0.2 \%$ Triton X-100 in PBS for $10 \mathrm{~min}$ at room temperature, washed in PBS-1\% Tween-20 (PBS-T). The cells blocked with $2 \%$ goat serum in PBS-T for $30 \mathrm{~min}$ at room temperature were incubated with rabbit polyclonal anti-ssDNA antibody (a dilution of 1:200) for 45 min at room temperature. After washing three times in PBS$\mathrm{T}$, the cells were incubated with Alexa fluor 488-labeled goat anti-rabbit IgG antibody for $30 \mathrm{~min}$ at room temperature. After washing, the cells were observed by the fluorescence microscope. The DNA fragmentation analysis was carried out, as previously published (3). Briefly, B-1 cells were seeded at a density of $4 \times 10^{5}$ cells/100-mm dish in HMB medium. The following day (day 0), the medium was changed to the same conditions, as described above. On day 2, floating and attached cells were collected together and suspended in PBS. The following procedures were performed as described previously (3).

Western blotting. B-1F cells were seeded at a density of $5 \times 10^{5}$ cells $/ 60-\mathrm{mm}$ dish in $3 \mathrm{ml} \mathrm{HMB}$ medium. The following day (day 0 ), the medium was changed to fresh HMB or HMBE medium with or without various concentrations of Scutellaria baicalensis. On day 2, the cells were washed in PBS, scraped into CelLytic ${ }^{\mathrm{TM}}-\mathrm{M}$ mammalian cell lysis/ extraction reagent and incubated for $15 \mathrm{~min}$ at $4^{\circ} \mathrm{C}$. Cell lysates were centrifuged at $17,000 \mathrm{xg}$ for $15 \mathrm{~min}$ at $4^{\circ} \mathrm{C}$. The supernatants were recovered and their protein concentrations were measured. Equivalent amounts of protein $(30 \mu \mathrm{g})$ were boiled in NuPAGE sample buffers, separated by $12 \%$ SDSPAGE and electrotransferred to PVDF membrane, using a semidry transfer blotting apparatus (Nippon Eido Co.). The membrane was washed with TBS-T (50 mM Tris- $\mathrm{HCl}, \mathrm{pH} 7.4$, $150 \mathrm{mM} \mathrm{NaCl}$ containing $0.1 \%$ Tween-20) for $5 \mathrm{~min}$ and blocked with TBS-T containing 5\% (wt/vol) non-fat dry milk for $60 \mathrm{~min}$ at room temperature. After washing three times with TBS-T each the membrane was incubated with rabbit polyclonal anti-cleaved caspase- 3 antibody (a dilution of 1:1000) in TBS-T containing $5 \%$ non-fat dry milk at $4{ }^{\circ} \mathrm{C}$ overnight. Washed membrane in TBS-T was incubated with 


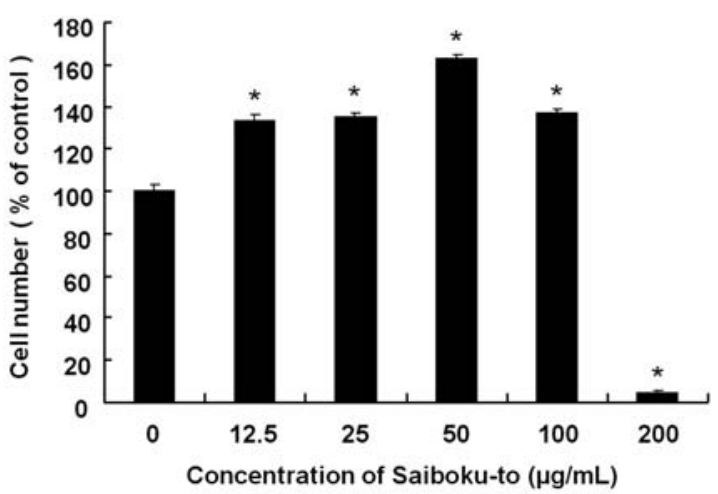

Figure 1. Effect of Saiboku-to on the proliferation of B-1F cells. B-1F cells were seeded onto $35-\mathrm{mm}$ dishes $\left(1 \times 10^{4}\right.$ cells/dish $)$ and treated with $0,12.5$, 25,50100 or $200 \mu \mathrm{g} / \mathrm{ml}$ of Saiboku-to in the absence of E2 for 6 days. The cultured medium was changed with the fresh medium containing test compounds every other day. The proliferation was estimated by counting the number of viable cells. Results are means of four determinations. Bars, SE The values are given as a percentage of the number per dish without Saiboku-to. The other five separate trials also gave similar results. ${ }^{*} \mathrm{P}<0.05$ vs. corresponding value without Saiboku-to.

secondary antibody of EnVision+/Peroxidase ${ }^{\mathrm{TM}}$ (rabbit) (a dilution of 1:100) for $60 \mathrm{~min}$ at room temperature. The membrane was washed and detected using ECL reagent kit.

RT-PCR analysis. B-1F cells were seeded at a density of $2 \times 10^{6}$ cells/100-mm dish in HMB medium. The following day (day 0), the medium was changed to HMB or HMBE medium with or without Scutellaria baicalensis. On day 3, total RNA was isolated from the cells using the TRIzol reagent, according to manufacturer's protocol. RT-PCR was performed as directed in the supplier manual (Ready-To-Go ${ }^{\mathrm{TM}} \mathrm{RT}-\mathrm{PCR}$ Beads) using specific primers. Mouse bcl-2 primers are 5'ATCTTCTCCTTCCAGCCTGA-3' (forward) and 5'TCAGTCATCCACAGGGCGAT-3' (reverse) (the RT-PCR product is $386 \mathrm{bp}$ ). The $\mathrm{RT}$ profile was $42^{\circ} \mathrm{C}$ for $30 \mathrm{~min}$ and $95^{\circ} \mathrm{C}$ for $5 \mathrm{~min}$ and the PCR profile was $94^{\circ} \mathrm{C}$ for $45 \mathrm{sec}$, $55^{\circ} \mathrm{C}$ for $45 \mathrm{sec}$ and $72^{\circ} \mathrm{C}$ for $1 \mathrm{~min}$ for 30 cycles. RT-PCR for GAPDH was performed, as described in the previous study. Amplified products were incubated at $72^{\circ} \mathrm{C}$ for $10 \mathrm{~min}$ for final extension and separated on $2 \%$ agarose gel containing ethidium bromide $(0.5 \mu \mathrm{g} / \mathrm{ml})$ and visualized under UV light. Negative control incubated without template and primers at $95^{\circ}$ for $10 \mathrm{~min}$ to inactivate the reverse transcriptase showed no PCR product.

Immunohistochemistry for cleaved caspase-3. Detection of cleaved caspase-3 was performed by immunohistochemistry. $\mathrm{B}-1 \mathrm{~F}$ cells were seeded in four well chamber slides (Falcon) at a density of $2 \times 10^{4}$ cells/well in HMB medium. The following day (day 0), the medium was changed to fresh HMB or HMBE medium with or without $25 \mu \mathrm{g} / \mathrm{ml}$ Scutellaria baicalensis. On day 3 , cells were washed in TBS and fixed in $4 \%$ paraformaldehyde for $15 \mathrm{~min}$. After washing in TBS, slides were incubated with $0.2 \%$ Triton X-100 in TBS for $5 \mathrm{~min}$ at room temperature. Slides washed three times with TBS for 5 min were incubated with $0.1 \%$ sodium borohydride in TBS for $5 \mathrm{~min}$ and washed in TBS. Slides were treated with blocking buffer (TBS containing $10 \%$ goat serum and $1 \% \mathrm{BSA}$ ) for $60 \mathrm{~min}$ at room temperature, washed and incubated with rabbit polyclonal anti-cleaved caspase- 3 antibody (a dilution of 1:100) in TBS containing 1\% BSA at $4^{\circ} \mathrm{C}$ overnight. After washing, slides were incubated with EnVision+/Peroxidase (mouse) for $30 \mathrm{~min}$ at room temperature and then incubated with diaminobenzidine tetrahydrochloride (DAB) until desired stain intensity developed. Slides rinsed with TBS were counterstained with hematoxylin for 1 min, washed, dehydrated through alcohols and xylene, mounted, and observed by a light microscope. Paraffinembedded tissue sections on slides were deparaffinized in xylene using three changes for $5 \mathrm{~min}$ each. Slides were incubated with $0.3 \% \mathrm{H}_{2} \mathrm{O}_{2}$ in methanol for $30 \mathrm{~min}$ at room temperature and washed with running water for $5 \mathrm{~min}$. Slides placed in a container with $1 \mathrm{mM}$ EDTA ( $\mathrm{pH} 8.0$ ) were microwaved for $15 \mathrm{~min}$ and cooled at room temperature for 30 min. After washing with running water and twice with PBS for 2 min each, slides were incubated with primary antibody as described above at room temperature overnight and washed three times with PBS for 2 min each. The following procedures were similar to those described above.

Materials. The materials were mainly purchased from the same sources as described previously (3). Anti-ssDNA antibody was purchased from Dako (Kyoto, Japan); ApopLadder EX ${ }^{\mathrm{TM}}$ from Takara (Shiga, Japan); labeled goat anti-rabbit IgG antibody (Alexa 488) from Molecular Probes, Inc (Oregon, OR); CelLytic ${ }^{\mathrm{TM}}$-M Mammalian Cell Lysis/ Extraction Reagent from Sigma Chemical Co. (St. Louis, MO); anti-cleaved caspase-3 (Asp175) antibody from Cell Signaling Technology; Inc. (Beverly MA); TRIzol reagent from Gibco BRL (Rockville, MD); Ready-To-Go ${ }^{\text {TM }}$ RT-PCR Beads and ECL Western blotting kit from GE Healthcare UK Ltd (NA, UK). Powder forms of Saiboku-to and its components were supplied by Tsumura Co. (Tokyo, Japan).

Statistics. The data were expressed as mean \pm standard error (SE). Data were analyzed by ANOVA with Dunnett's or Bonferroni's corrections for multiple comparisons, as appropriate. Calculated $\mathrm{p}$-values of $<0.05$ were considered to be significant.

\section{Results}

Effect of Saiboku-to on B-1F cell proliferation. B-1F cells were incubated with various concentrations of Saiboku-to having suppressive activities of LT production and release. Following the treatment of B-1F cells with Saiboku-to, on day 6 , the cell proliferation was determined by the yield of viable cells. When B-1F cells were treated with Saiboku-to in the absence of E2, the cell proliferation was increased in a dose-dependent manner (Fig. 1). At the concentration of $50 \mu \mathrm{g} / \mathrm{ml}$ of extract it was increased to 1.6-fold of control (no addition of extract).

Identification of components in Saiboku-to affecting B-1F cell proliferation. Saiboku-to is composed of ten components (herbs); Latin names are Bupleuri Radix, Pinelliae Tuber, Hoelen (Poria), Scutellariae Radix (scientific name is 


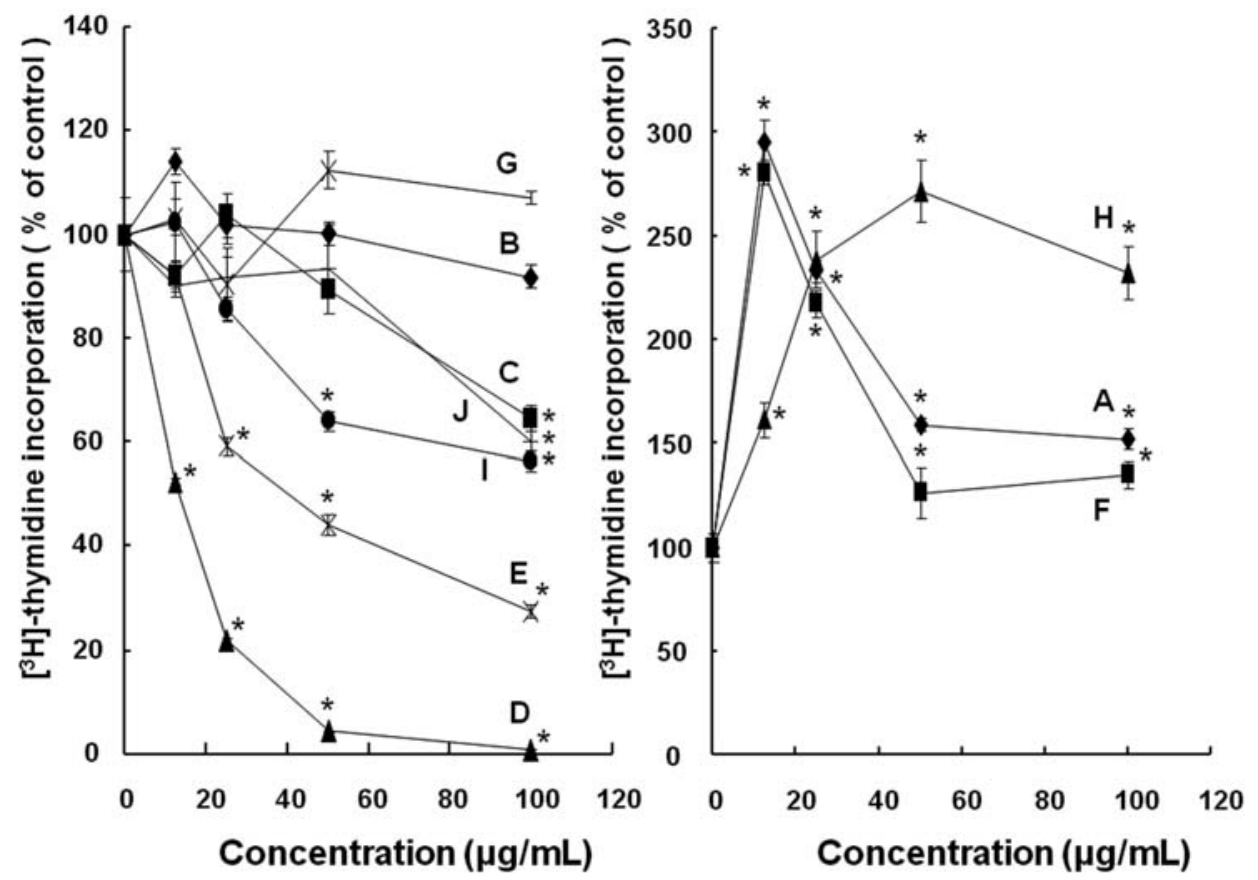

Figure 2. Effects of ten herbs contained in Saiboku-to on the proliferation of B-1F cells. B-1F cells were seeded onto 96 -plate $\left(5 \times 10^{3}\right.$ cells/well). The following day (day 0) the medium was replaced with HMB medium containing 0,12.5, 25, 50 or $100 \mu \mathrm{g} / \mathrm{ml}$ of each herb, Bupleuri Radix (A), Pinelliae Tuber (B), Hoelen (Poria) (C), Scutellariae Radix (D), Magnoliae Cortex (E), Zizyphi Fructus (F), Ginseng Radix (G), Glycyrrhizae Radix (H), Perillae Herba (I) and Zingiberis Rhizoma (J), in the absence of E2. On day 3, the incorporation of $\left[{ }^{3} \mathrm{H}\right]$-thymidine into the cells was measured. Results are means of four determinations. Bars, SE. The values are given as a percentage of the thymidine incorporation per well without test compound. The other two separate trials also gave similar results. ${ }^{*} \mathrm{P}<0.05$ vs. corresponding value without herb.

A
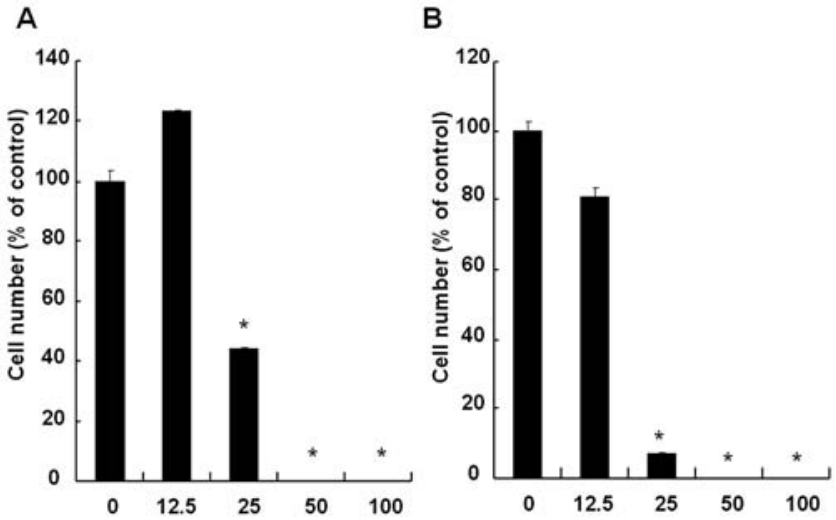

Concentration of S. baicalensis $(\mu \mathrm{g} / \mathrm{mL})$ Concentration of S. baicalensis $(\mu \mathrm{g} / \mathrm{mL})$

Figure 3. Effect of Scutellaria baicalensis on the proliferation of B-1F cells $\mathrm{B}-1 \mathrm{~F}$ cells were seeded onto $35-\mathrm{mm}$ dishes $\left(1 \times 10^{4}\right.$ cells/dish) and treated with $0,12.5,25,50$ or $100 \mu \mathrm{g} / \mathrm{ml}$ of Scutellaria baicalensis in the absence (A) or presence of E2 (B) for 6 days. The cultured medium was changed with the fresh medium containing test compounds every other day. The proliferation was estimated by counting the number of viable cells. Results are means of four determinations. Bars, SE. The values are given as a percentage of the number per dish without test compound. The other three separate trials also gave similar results. ${ }^{*} \mathrm{P}<0.05$ vs. corresponding value without Scutellaria baicalensis.

Scutellaria baicalensis ), Magnoliae Cortex, Zizyphi Fructus, Ginseng Radix, Glycyrrhizae Radix, Perillae Herba and Zingiberis Rhizoma in 7.0, 5.0, 5.0, 3.0, 3.0, 3.0, 3.0, 2.0, 2.0, 1.0 parts (Tsumura). In order to know which component affects $\mathrm{B}-1 \mathrm{~F}$ cell proliferation, cells were incubated with various concentrations $(0-100 \mu \mathrm{g} / \mathrm{ml})$ of each herb. Following the treatment of B-1F cells with herbs for three days, the cell proliferation was determined by $\left[{ }^{3} \mathrm{H}\right]$-thymidine incorporation into cells. As shown in Fig. 2, Bupleuri Radix (A), Zizyphi Fructus $(\mathrm{F})$ and Glycyrrhizae Radix $(\mathrm{H})$ increased B-1F cell proliferation, but Scutellariae Radix (D), Magnoliae Cortex (E), Perillae Herba (I), Zingiberis Rhizoma (J) and Hoelen (Poria) (C) inhibited it. The most effective herb, Scutellaria baicalensis (Latin name is Scutellariae Radix), almost completely inhibited B-1F cell proliferation at 50-100 $\mu \mathrm{g} / \mathrm{ml}$. We examined effects of Scutellaria baicalensis with or without E2 on B-1F cell proliferation (Fig. 3). Growthinhibitory effect of Scutellaria baicalensis was observed under both conditions, although Saiboku-to increased B-1F cell proliferation. Effects of lack of one herb or both the herb and Scutellaria baicalensis from Saiboku-to on the proliferation were studied. Combination effects of herbs contained in Saiboku-to are shown in Fig. 4. The proliferation was inhibited when the cells were treated with Saiboku-to lacking Bupleuri Radix (A), Pinelliae Tuber (B) or Hoelen (C) (Fig. 4A). But this inhibition was partly recovered when treated with Saiboku-to lacking both Scutellaria baicalensis (D) and Bupleuri Radix (A) or Pinelliae Tuber (B) (SBT-A vs. SBT-A-D, SBT-B vs. SBT-B-D; statistically significant).

Suppression of in vivo B-1F cell growth by Scutellaria baicalensis. Following the detection of the anti-proliferative activity of Scutellaria baicalensis in vitro, in vivo experiment was carried out. As shown in Fig. 5, tumors were palpable after 2 weeks of B-1F cell injection and their growth was accelerated by E2, which was inhibited by Scutellaria 
A

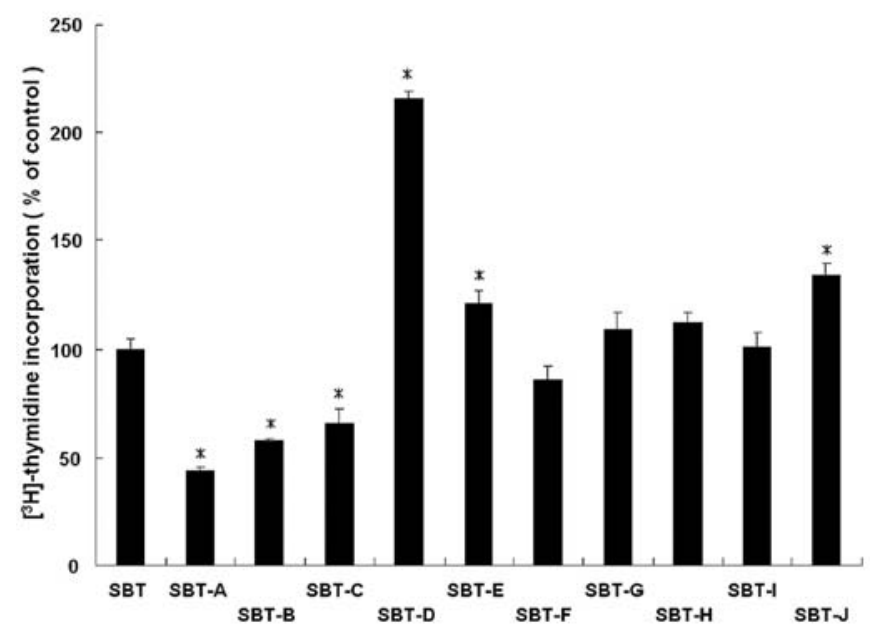

B

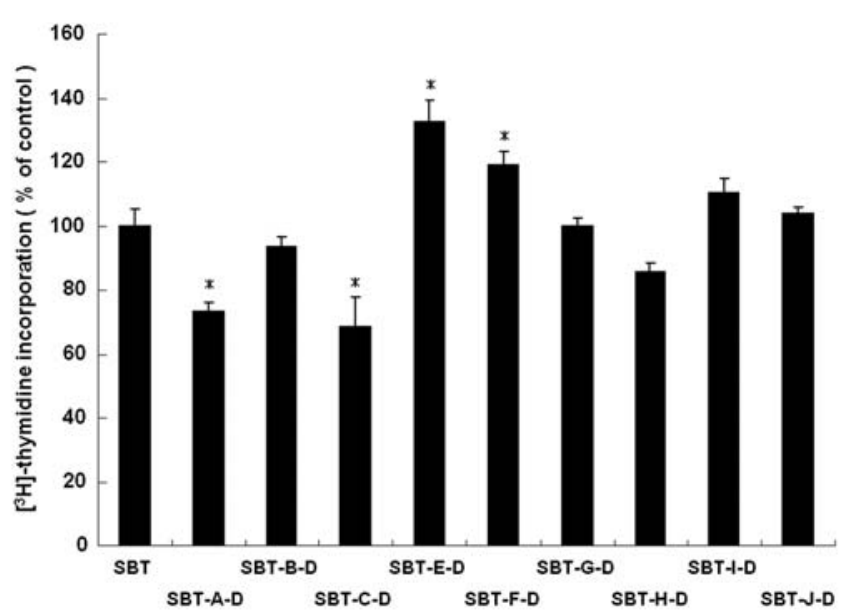

Figure 4. Effects of various combinations of herbs in Saiboku-to on the proliferation of B-1F cells. Effects of lack of one herb (A) or both the herb and Scutellaria baicalensis (B) from Saiboku-to on the proliferation were studied. B-1F cells were seeded onto a 96-plate (5x10 3 cells/well). The following day (day 0) the medium was replaced with HMB medium containing $100 \mu \mathrm{g} / \mathrm{ml}$ of combinations of herbs in Saiboku-to. On day 3, the cells were pulsed with $\left[{ }^{3} \mathrm{H}\right]$-thymidine for $2 \mathrm{~h}$ at $37^{\circ} \mathrm{C}$. The incorporation of radioactivity into the cells was measured. Results are means of four determinations. Bars, SE. The values are given as a percentage of the thymidine incorporation per well without test compound. The other two separate trials also gave similar results. ${ }^{*} \mathrm{P}<0.05$ vs. corresponding value with Saiboku-to.

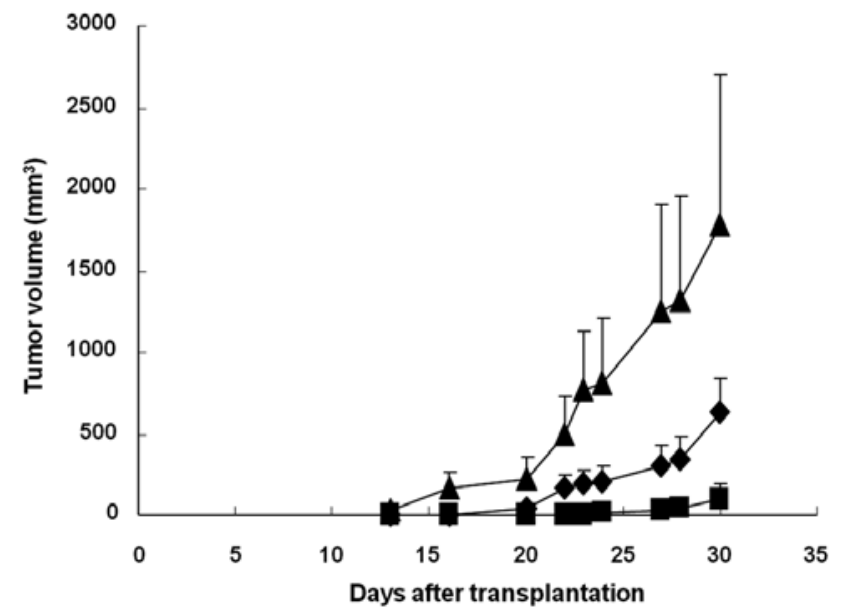

Figure 5. Suppressive effect of Scutellaria baicalensis on the in vivo growth of B-1F cells. B-1F cells were subcutaneously inoculated into castrated male Balb/c mice. The following day (day 0), mice were implanted a fused pellet of $1 \% \mathrm{E} 2$ and feeding with or without Scutellaria baicalensis was started. The tumors were measured. Results are means \pm SE of five (None) and six determinations (E2, E2 + Scutellaria baicalensis). • E2; $\bullet, \mathrm{E} 2+$ Scutellaria baicalensis; $\mathbf{\square}$, None. The other two separate trials also gave similar results.

baicalensis p.o. On day 30, tumor volumes in mice were 98.5 \pm 98.5 (None) and 630.4 \pm 211.7 (E2 + Scutellaria baicalensis) or $1780.0 \pm 914.4$ (E2) $\mathrm{mm}^{3}$, respectively. During in vivo experiment, body weight of mice and amounts of drinking water were measured at indicated intervals. Neither was significantly changed by Scutellaria baicalensis (data not shown). These results showed the anti-proliferative activity of Scutellaria baicalensis in vivo as well as in vitro although statistic significance was not observed in data shown in Fig. 5 due to large variation.
Effect of Scutellaria baicalensis and Saiboku-to on the binding of estrogen to its binding sites in B-1F cells. Scutellaria baicalensis contains flavonoids, mainly baicalin, baicalein and wogonin (15). These flavonoids are known to bind to estrogen receptor (ER) and cause estrogen-like action $(16,17)$. We examined whether Scutellaria baicalensis competed with E2 for estrogen binding sites in B-1F cells, using whole cell and cell-free binding assays. The results are shown in Fig. 6. When B-1F cells were incubated with various concentrations of Scutellaria baicalensis, the binding of $\left[{ }^{3} \mathrm{H}\right] \mathrm{E} 2$ to estrogen binding sites was not affected. The competition assay between $\left[{ }^{3} \mathrm{H}\right] \mathrm{E} 2$ and Saiboku-to was also performed. The result was similar to that between $\left[{ }^{3} \mathrm{H}\right] \mathrm{E} 2$ and Scutellaria baicalensis.

Induction of apoptosis in B-1F cells by Scutellaria baicalensis. Morphological changes were studied in B-1F cells treated with Scutellaria baicalensis in the presence or absence of E2. As shown in Fig. 7A, when treated B-1F cells were stained with Hoechst 33342, nuclear aggregation and fragmentation were observed. Immunocytochemical staining with the antibody for ssDNA demonstrated more positive staining in B-1F cells treated with than in those without Scutellaria baicalensis (Fig. 7B). Induction of DNA fragmentation was also observed (Fig. 8A). Detection of cleaved caspase-3 was performed using Western blotting (Fig. 8B) and immunohistochemistry (Fig. 9). $\mathrm{B}-1 \mathrm{~F}$ cells without E2 stimulation showed more increased expression of cleaved caspase- 3 than those with E2. A reason might be that $\mathrm{B}-1 \mathrm{~F}$ cell proliferation is responsive to $\mathrm{E} 2$. As shown in Fig. 8C, expression of bcl-2 mRNA was significantly decreased in treated B-1F cells.

\section{Discussion}

Although Saiboku-to promoted B-1F cell proliferation, Scutellaria baicalensis, a component of Saiboku-to, was found 
A
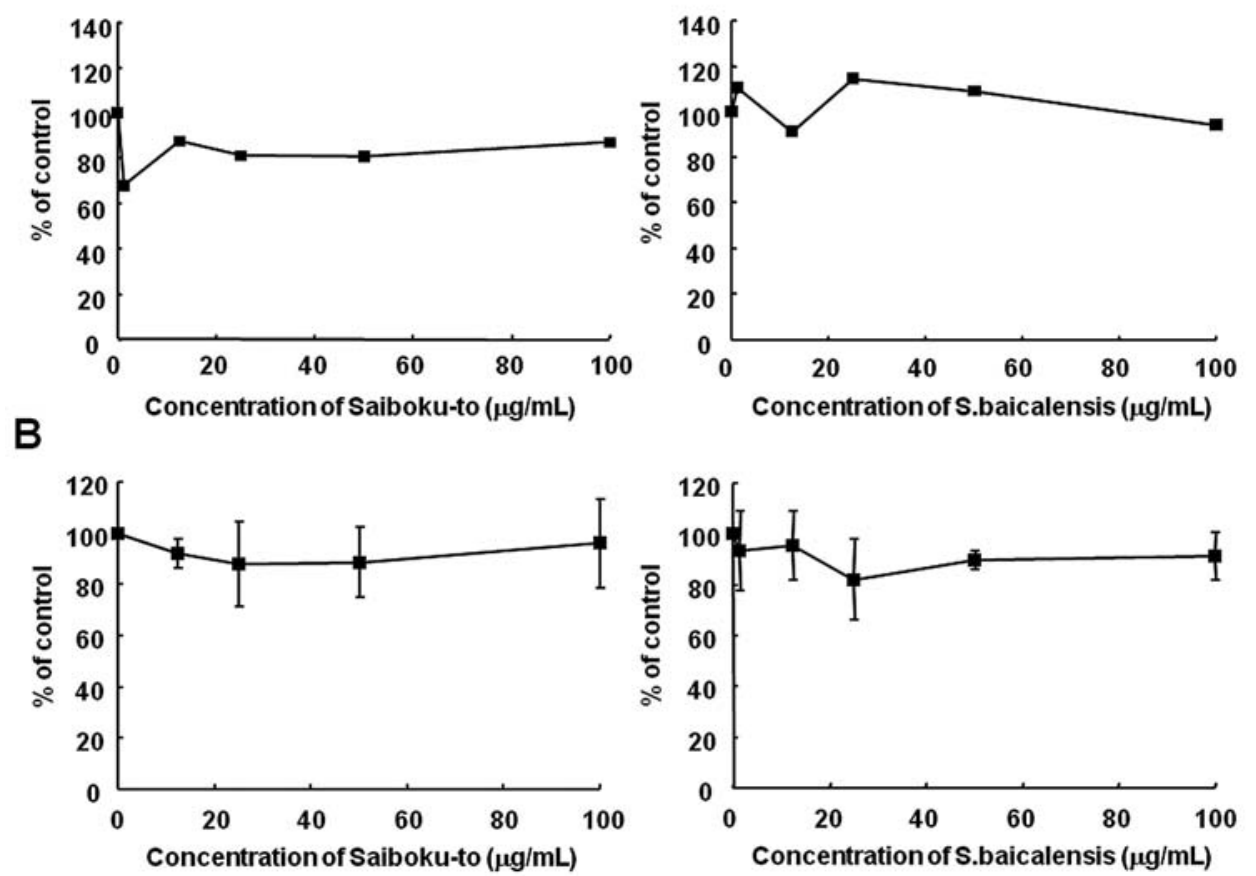

Figure 6. Effects of Scutellaria baicalensis and Saiboku-to on the binding of estrogen to its binding sites. [ $\left.{ }^{3} \mathrm{H}\right] \mathrm{E} 2$-estrogen binding assays were carried out as described in Materials and methods. $\left[{ }^{3} \mathrm{H}\right] \mathrm{E} 2$ binding to B-1F cells (A) were determined in the presence of various concentrations of Saiboku-to (left) or Scutellaria baicalensis (right) as a competitor. The radioactivity binding to washed cells was determined. Values are means of experiments performed in duplicate. The other two separate trials also gave similar results. Results from cell-free binding assay are also shown (B). The binding was expressed as a percentage of control (no competitor). Values are means \pm SE of three experiments.

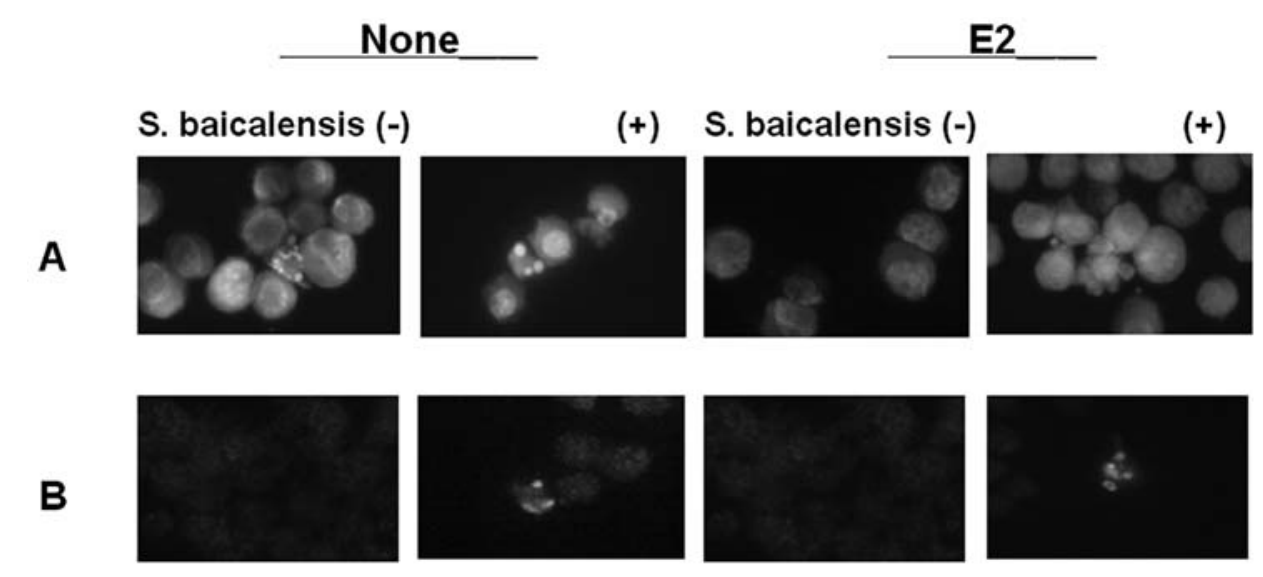

Figure 7. Detection of apoptosis using Hoechst 33342 and antibody for ssDNA. B-1F cells were treated as described in Materials and methods. (A), Hoechst 33324; (B), ssDNA.

to suppress it. Down-regulation of bcl-2 and activation of caspase- 3 in treated B-1F cells indicates that Scutellaria baicalensis induces apoptosis through the activation of mitochondria pathway.

When B-1F cells were treated with Saiboku-to lacking Scutellaria baicalensis, their proliferation was increased. The cell proliferation was inhibited when the cells were treated with Saiboku-to lacking Bupleuri Radix (A) or Pinelliae Tuber (B). This inhibition was partly recovered by the additional elimination of Scutellaria baicalensis from Saiboku-to, suggesting potential growth inhibitory activity of Scutellaria baicalensis. We examined effects of many combinations, but did not examine all combinations. Therefore, it is possible that other combinations have unknown effects.

In vitro and in vivo experiments with Scutellaria baicalensis strongly inhibited the growth of B-1F cells. Scutellaria baicalensis contains many flavonoids (15), which are known to show estrogenic action following the binding to ER $(16,17)$. The results from whole cell and cell-free binding assays showed that Scutellaria baicalensis had no direct action on estrogen binding sites in B-1F cells. Binding of Scutellaria baicalensis to estrogen binding sites was too weak to fully compete with estrogen. Similar results were obtained for Saiboku-to, suggesting that in B-1F cells 
A

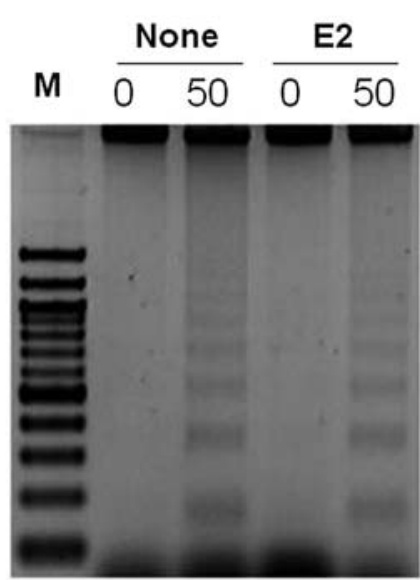

B

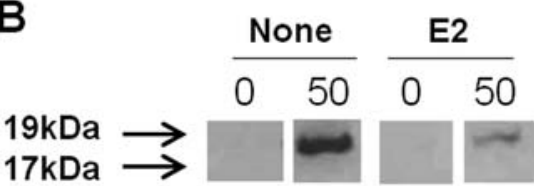

C

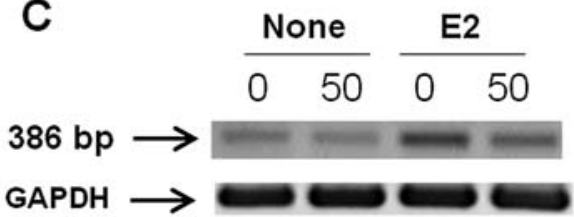

Figure 8. Apoptosis caused by Scutellaria baicalensis in B-1F cells. Effect of Scutellaria baicalensis on DNA fragmentation in B-1F cells is shown (A). Detection of DNA fragmentation was carried out as described in Materials and methods. B-1F cells were seeded onto $100-\mathrm{mm}$ dishes $\left(4 \times 10^{5}\right.$ cells/dish). The following day (day 0) the medium was changed to HMB medium with or without Scutellaria baicalensis in the presence or absence of E2. None, no E2. (B) Western blot analysis of expression of cleaved caspase-3 in treated B-1F cells is shown. (C) expression of bcl-2 mRNA in treated B-1F cells is shown. GAPDH, glyceraldehyde-3-phosphate dehydrogenase.
Saiboku-to and Scutellaria baicalensis do not act via ER, but via another pathway and that Scutellaria baicalensis potentially induces apoptosis of B-1F cells. In $\mathrm{LNCaP}$ and PC-3 cells, prostate cancer cell lines, Scutellaria baicalensis and its constituents (baicalein, wogonin, neobaicalein and skullcapflavone) inhibited their proliferation, together with suppressive effect on androgen receptor signaling and cell cycle at G1 phase (18). In SCC-25 and KB cells, heat and neck squamous cell carcinoma (HNSCC) cell lines, Scutellaria baicalensis inhibits the cell proliferation and PGE2 synthesis and induces cell cycle arrest at G1-G0 phase due to the inhibition of cyclo-oxygenase-2 (COX-2) expression (19). Baicalein is known to be a 12-lipoxygenase (12-LOX) inhibitor (20) and 5,6,7-trimethylbaicalein derivative is reported to inhibit the cell proliferation (21). Although the mechanism of action of Scutellaria baicalensis in B-1F cells is not known, the present study indicates Scutellaria baicalensis or its constituents might be a good resource for searching new drugs, especially anti-cancer drugs. The mechanism is necessary to be studied.

A traditional Chinese medicine is a combination of various herbs. For example, Saiboku-to in this study is composed of ten herbs. In addition, each herb consists of many chemical constituents. Therefore, effects of a traditional Chinese medicine are not only those by a single herb or a single constituent of herb, but also effects that various actions such as interaction, potentiation, antagonistic action, reciprocal antagonism, suppression of toxicity and counteraction among herbs are put together. In our present study, Saiboku-to promoted B-1F cell proliferation, but Scutellaria baicalensis, a component of Saiboku-to, inhibited it, showing complexity of action of traditional Chinese medicines.
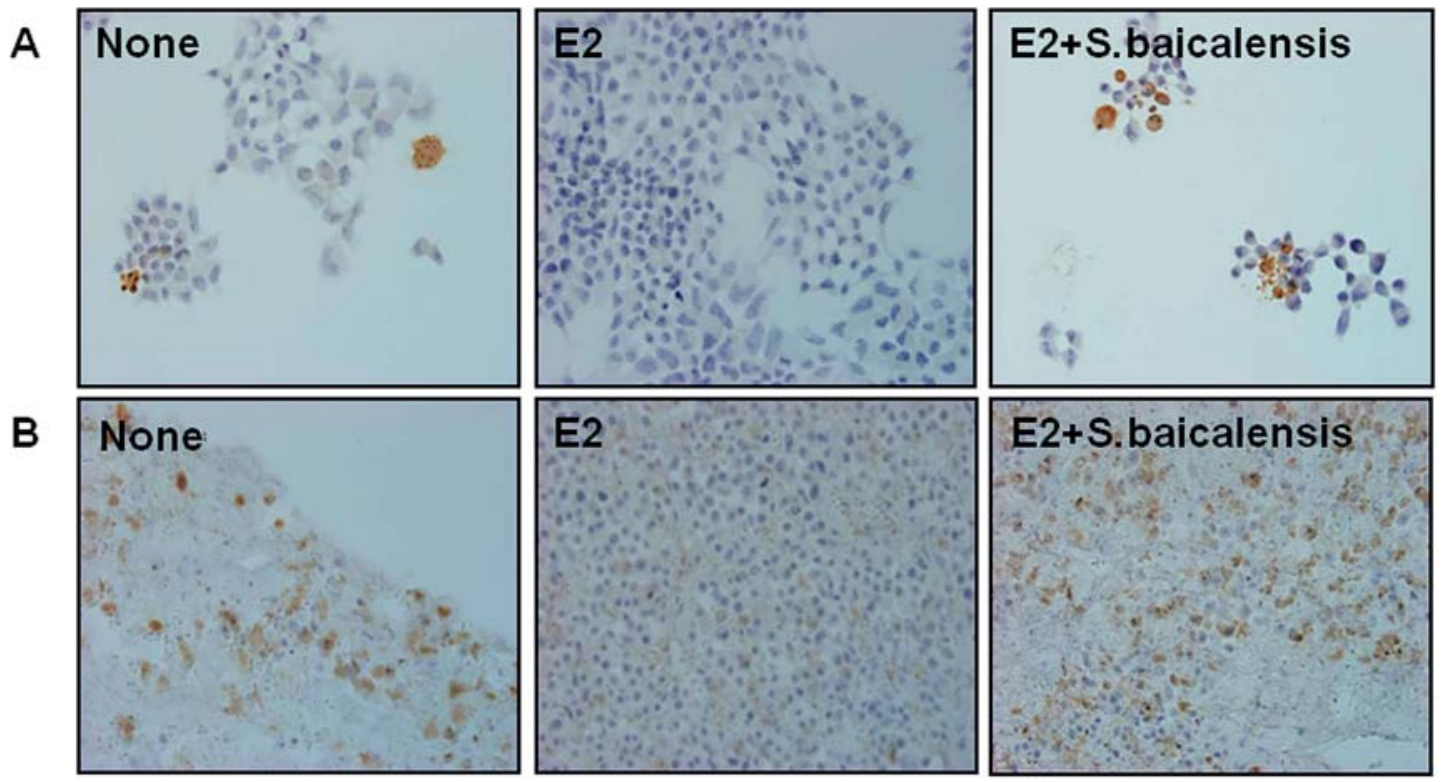

Figure 9. Immunohistochemistry for cleaved caspase-3 in treated B-1F cells. The cells were seeded onto four chamber slides ( $2 \times 10^{4}$ cells/well) and treated with Scutellaria baicalensis. On day 3, caspase activation of the treated cells was studied by immunohistochemistry for cleaved caspase-3 (A). Paraffin sections from in vivo tumors were also stained (B). 


\section{Acknowledgements}

The technical assistance of Mrs. K. Miyazono, K. Ueyama and T. Tsuji is gratefully acknowledged.

\section{References}

1. Hong SH, Avis I, Vos MD, Martinez A, Treston AM and Mulshine JL: Relationship of arachidonic acid metabolizing enzyme expression in epithelial cancer cell lines to the growth effect of selective biochemical inhibitors. Cancer Res 59: 2223-2228, 1999.

2. Shureiqi I and Lippman SM: Lipoxygenase modulation to reverse carcinogenesis. Cancer Res 61: 6307-6312, 2001.

3. Goto HG, Nishizawa Y, Katayama H, et al: Induction of apoptosis in an estrogen-responsive mouse Leydig tumor cell by leukotriene. Oncol Rep 17: 225-232, 2007.

4. Nishizawa Y, Yamamoto T, Terada N, Fushiki S, Amakata Y and Nishizawa Y: Effects of antiallergic drugs on the proliferation of estrogen-sensitive mouse Leydig cell line. Anticancer Res 16: 1241-1246, 1996.

5. Nishizawa Y, Nishizawa Y, Yamamoto T, et al: Progression of mouse transformed Leydig cells from estrogen-sensitive to estrogen-insensitive growth phenotype concomitant with loss of leukotriene D4 receptor. Int J Oncol 5: 1077-1084, 1994.

6. Sato B, Hirose T, Kasayama S, Takabayashi H, Koga M and Nishizawa Y: Transformed murine Leydig cells in serum-free culture: useful model for analysis of steroid hormone-induced cell growth and cell morphology (Review). Int J Oncol 1: 415-423, 1992.

7. Nishizawa Y, Yamamoto T, Taniguchi H and Sato B: Effects of estrogen and leukotrienes on anchorage-independent growth of transformed mouse Leydig cells under serum-free condition. Steroid Biochem (Life Sci Adv) 11: 23-28, 1992.

8. Nishii K, Nishizawa Y, Nishizawa Y, Matsumoto K and Sato B: Inhibition of murine transformed Leydig cell proliferation by leukotrienes in serum-free culture. Cancer Res 51: 5573-5578, 1991.

9. Nishizawa Y, Nishii K, Nishizawa Y, et al: Effects of estrogen on cell proliferation and leukotriene formation in tansformed mouse Leydig cells cultured under serum-free conditions. Cancer Res 50: 3866-3871, 1990.
10. Nishizawa Y, Nishii K, Kishimoto S, Matsumoto K and Sato B: Regulatory role of arachidonic acid-derived matabolites for proliferation of transformed murine Leydig cell in serum-free culture condition. Anticancer Res 10: 317-322, 1990.

11. Miyata T: Pharmacological basis of traditional medicines and health supplements as curatives. J Pharmacol Sci 103: 127-131, 2007.

12. Borchers AT, Hackman RM, Keen CL, Stern JS and Gershwin ME: Complementary medicine: a review of immunomodulatory effects of Chinese herbal medicines. Am J Clin Nutr 66: 1303-1312, 1997.

13. Villa E, Dugani A, Fantoni E, et al: Type of estrogen receptor determines response to antiestrogen therapy. Cancer Res 56: 3883-3885, 1996.

14. Nishizawa Y, Sato B, Nishii K, Kishimoto S and Matsumoto K: Effect of androgen on proliferation of estrogen-responsive transformed mouse Leydig cells in serum-free culture. Cancer Res 49: 1377-1382, 1989

15. Zuo F, Zhou ZM and Liu ML: Determination of 14 chemical constituents in the traditional Chinese medicinal preparation Huangqin-Tang by high performance liquid chromatography. Biol Pharm Bull 24: 693-697, 2001.

16. Chan RY, Chen WF, Dong A, Guo D and Wong MS: Estrogenlike activity of ginsenoside Rg1 derived from Panax notoginseng. J Clin Endocrinol Metab 87: 3691-3695, 2002.

17. Han DH, Denison MS, Tachibana H and Yamada K: Relationship between estrogen receptor-binding and estrogenic activities of environmental estrogens and suppression by flavonoids. Biosci Biotechnol Biochem 66: 1479-1487, 2002.

18. Bonham M, Posakony J, Coleman I, Montgomery B, Simon J and Nelson PS: Characterization of chemical constituents in Scutellaria baicalensis with antiandrogenic and growthinhibitory activities toward prostate carcinoma. Clin Cancer Res 11: 3905-3914, 2005

19. Zhang DY, Wu J, Ye F, et al: Inhibition of cancer cell proliferation and prostaglandin E2 synthesis by Scutellaria baicalensis. Cancer Res 63: 4037-4043, 2003.

20. Abe $\mathrm{M}$ and Yoshimoto T: Leukotriene-lipoxygenase pathway and drug discovery. Nippon Yakurigaku Zasshi 124: 415-425, 2004.

21. Liao HL and Hu MK: Synthesis and anticancer activities of 5,6,7-trimethylbaicalein derivatives. Chem Pharm Bull 52: 1162-1165, 2004. 